\title{
Normotensive cardiomyopathy and malignant hypertension in phaeochromocytoma
}

\author{
L. M. SHAPIRO \\ M.D., M.R.C.P.
}

\author{
N. TRETHOWAN \\ M.B., M.R.C.P.
}

\begin{abstract}
Summary
A patient with two different presentations of phaeochromocytoma is described. She initially presented with normal blood pressure and heart failure following a prolonged feverish prodrome. A provisional diagnosis of myocarditis or early congestive cardiomyopathy was made and she improved with digoxin and diuretics. Eighteen months later, after a period of normotension free from heart failure, she developed malignant hypertension with recurrence of heart failure. A phaeochromocytoma was surgically removed, with return to normal of blood pressure and cardiac status. It would seem that the initial presentation of the phaeochromocytoma was a catecholamineinduced myocarditis without hypertension and this resolved with the subsequent development of malignant hypertension. The possible mechanisms responsible for this are discussed and it is concluded that phaeochromocytoma should be considered in patients who have heart failure and persistent features of myocarditis.
\end{abstract}

\section{Introduction}

Phaeochromocytomas are rare tumours with a constellation of clinical features dominated by hypertension, due to the constant or paroxysmal release of pressor catecholamines (Engleman, 1977); myocarditis and congestive heart failure may also directly result from the action of these agents (Vliet, Burchell and Titus, 1966). The case presented illustrates that a normotensive patient with phaeochromocytoma and congestive heart falure may produce diagnostic problems.

\section{Case report}

A 30-year-old married woman who was born in India presented in September 1978 with a 6-week history of dry cough, profuse nocturnal sweating, exertional dyspnoea and ankle oedema. There was no family or past history of note. She had a swinging. pyrexia $\left(37-39.6^{\circ} \mathrm{C}\right.$ ), persistent tachycardia (heart $\vec{\circ}$ rate varying from 106 to 138 beats/min) and blood。 pressure between $105 / 65$ and $122 / 78 \mathrm{mmHg}$ on more than twenty occasions. Jugular venous pressure was raised $7 \mathrm{~cm}$, and third and fourth $\mathbb{D}$ heart sounds were heard but no other abnormalities? were noted on physical examination. Chest radio-卷 graphy showed an enlarged cardiac silhouette angd the electrocardiogram showed inferior and late lead ST segment depression and $T$ wave inversio ? An echocardiogram showed normal wall and sept圂 thickness, enlargement of the left atrium and ventricle with reduced shortening. The activity of aspartate aminotransferase was raised to 245 i.u./ $/ \stackrel{2}{\circ}$ (normal 45 i.u./l), metanephrine excretion was not ${ }_{\stackrel{\complement}{\complement}}^{\mathbb{D}}$ estimated and all other biochemical, endocrino- $\overrightarrow{\vec{P}}$ logical and microbiological investigations were $\frac{3}{3}$ normal. A provisional diagnosis of viral myocarditis or early congestive cardiomyopathy was made, ando she was treated with digoxin and diuretics with gradual symptomatic improvement and no change 3 in blood pressure. No rise in viral antibody titres; was shown.

She was regularly reviewed and became asymptomatic by November 1978 with a normal chest radiograph. Her blood pressure was recorded untilo February 1979 at between $112 / 74$ and $128 / 82 \mathrm{mmHg}$. However, in April 1979 heart failure recurred and 0 she was noted to be very anxious with a blood pressure of $205 / 142 \mathrm{mmHg}$, and to have retinal o exudates, haemorrhages and papilloedema. In- N vestigation revealed raised urinary metanephrine స్ excretion at $42.4 \mu \mathrm{mol} / \mathrm{l} 24 \mathrm{hr}$ (normal $9.3 \mu \mathrm{mol} / \frac{\mathrm{\omega}}{\sigma}$ $24 \mathrm{hr}$ ) with metadrenaline at $980 \mu \mathrm{g} / \mathrm{g}$ of creatinine (normal 130), and nor-metadrenaline at $2964 \mu \mathrm{g} / \mathrm{g}$ of $\stackrel{\circ}{\stackrel{C}{\odot}}$ creatinine (normal 220). Arteriography showed a $\stackrel{\mathbb{D}}{\rightleftharpoons}$ left suprarenal mass. A $70 \mathrm{~g}$ phaeochromocytoma was excised and subsequently the blood pressure, 
radiographic heart size, electrocardiogram and echocardiogram returned to normal and she has remained well since.

\section{Discussion}

Hypertension with or without retinal changes, myocarditis or congestive heart falure are well recognized features of phaeochromocytoma (Engleman, 1977). An interesting aspect of this case was the development and resolution of heart failure with entirely normal blood pressure before the development of malignant hypertension. The diagnosis of viral myocarditis or early congestive cardiomyopthy is often difficult to make but the clinical features of pyrexia, tachycardia and heart failure following a feverish prodrome are highly suggestive even in the absence of rising viral titres (Braunwald, 1980); However, in the light of subsequent events, this initial episode may have been due to a catecholamine-induced myocarditis.

Excess catecholamine secretion may induce hypertrophy, disseminated focal degeneration and necrosis of myocardium (Vliet et al., 1966). This may result in acute and chronic heart failure, occasionally in the absence of hypertension (Baker $e t$ al., 1972). In the case presented, electro- and echocardiograms revealed no hypertrophy and this illustrates that, although left ventricular hypertrophy is described as a feature of catecholamine myocarditis (Vliet et al., 1966), this is due to associated hypertension. It has been recently shown that myocardial hypertrophy is absent in some cases of malignant hypertension due to other causes (Shapiro, Mackinnon and Beevers, 1981), and this patient confirms that the malignant phase may be of rapid onset and not preceded by a prolonged non-malignant phase. Excessive catecholamine action is almost certainly the cause of left ventricular disease in phaeochromocytoma and is one hypothesis for the evolution of congestive cardiomyopathy (Swedberg et al., 1980).

Thus, this case has unusual features with two different presentations of phaeochromocytoma possibly owing to variations in the amount and relative concentratons of adrenaline and noradrenaline, and integrates some aspects of the development and resolution of congestive cardiomyopathy and nonhypertrophic malignant hypertension. There were no specific features to indicate the aetiology of the initial heart failure. However, the symptoms and signs of active myocarditis were rather prolonged and it is concluded that the diagnosis of phaeochromocytoma should be considered in cases of heart failure of unknown aetiology.

\section{References}

Baker, G., Zeller, N.H., Weitzner, S. \& Leach, J.K. (1972) Pheochromocytoma without hypertension presenting as cardiomyopathy American Heart Journal, 83, 688.

Braunwald, E. (1980) Heart Disease. A Textbook of Cardiovascular Medicine, pp. 1437-1500. W. B. Saunders, London.

Engelman, K. (1977) Phaeochromocytoma Clinical Endocrinology and Metabolism, 6, 769.

Shapiro, L.M., Mackinnon, J. \& Beevers, D.G. (1981) Echocardiographic features of malignant hypertension. British Heart Journal, 46, 374.

Swedberg, K., Hualmarson, A., Waagstein, F. \& WalLENTIN, I. (1980) Beneficial effects of long-term betablockade in congestive cardiomyopathy. British Heart Journal, 44, 117.

Vliet, P.D.V., Burchell, H.B. \& Titus, J.L. (1966), Focal myocarditis associated with pheochromocytoma. New England Journal of Medicine, 274, 1102. 